Research Article

\title{
Effects of Smoke-Dust and CO on Controllable Circulatory Ventilation of an Extra-Long Highway Tunnel: Theoretical Model and Calculations
}

\author{
Feng Tian, ${ }^{1,2}$ Hai-qiao Wang, ${ }^{1}$ Shi-qiang Chen ${ }^{(D)},{ }^{1}$ and Yong-ping Chen ${ }^{3}{ }^{3}$ \\ ${ }^{1}$ School of Resource, Environment and Safety Engineering, Hunan University of Science and Technology, Xiangtan 411201, \\ Hunan, China \\ ${ }^{2}$ Tunnel Design Branch, China Railway Liuyuan Group Co. Ltd., Hongqiao 300133, Tianjin, China \\ ${ }^{3}$ Department of Building Environment and Energy Engineering, Guilin University of Aerospace Technology, Guilin 541004, \\ Guangxi, China \\ Correspondence should be addressed to Shi-qiang Chen; zunyichsq@163.com
}

Received 3 July 2018; Revised 29 August 2018; Accepted 3 September 2018; Published 22 October 2018

Guest Editor: Guo-zhong $\mathrm{Hu}$

Copyright (c) 2018 Feng Tian et al. This is an open access article distributed under the Creative Commons Attribution License, which permits unrestricted use, distribution, and reproduction in any medium, provided the original work is properly cited.

\begin{abstract}
The complexity, high energy consumption, and difficulty in controlling of extra-long highway tunnel have always been problematic in the civil engineering field. The objective of this study is to discuss controllable circulatory ventilation (CCV) considering these issues. By calculating the equations of consumed air volume (CAV), diluting smoke-dust and CO, this study deduces the theoretical dimensionless equations governing the influence of two pollutants' CAV on CCV application. By setting the vehicle speed from $10 \mathrm{~km} / \mathrm{h}$ to $80 \mathrm{~km} / \mathrm{h}$ and setting the slope from $-4 \%$ to $4 \%$, engineering data of Jiaozhouwan tunnel, for example, the abovementioned equations of environment ratio, load ratio, and critical diesel-gasoline ratio, were calculated numerically. Furthermore, the effects of smoke-dust and CO on CCV were quantified. Drawn from this study, the critical dieselgasoline ratio can be a key indicator to the preassessment of CCV application to an extra-long highway tunnel.
\end{abstract}

\section{Introduction}

With the rapid development of highway construction in China, a large number of extra-long highway tunnels are constantly emerging, while the required air volume of such tunnels is greatly increasing. To meet the increasing need of consumed air volume (CAV), the longitudinal ventilation of the supplying and exhausting shafts is generally adopted to draw in fresh air. Then, to dilute pollutants, this airflow mixes with or replaces the polluted air in the tunnel. Those pollutants are caused by fire in emergency. As far as the flame of fires, De Faveri et al. carried out an experimental study in a wind tunnel in order to provide exact correlations for predicting flame length of fires of high source and concluded that the length of laminar flames of fires of highsource momentum was affected not only by the source Froude number; on the contrary, the effect of the Reynolds number on the flame length was negligible if the Froude number was less than 0.1 [1]. This Froude number is the main cause of a flame length, but it also affects the movement of a smoke flow. Wang et al. suggested that with the decrease of smoke temperatures, some smoke might backflow and mix with the smoke-free layer below [2]. Furthermore, the above conclusions were proven by $\mathrm{Hu}$ et al. as far as methanol and gasoline pool fires [3]. In detail, Wang et al. observed that even though the pool surface area was kept identical for hollow trays of different sizes, the measured burning rates and fire evolutions were found to be significantly different [4]. Additionally, Tao et al. discussed an interesting flame-wrapping phenomenon caused by impingement of airflow [5]. Therefore, the Froude number was selected as a critical criterion of model experiments [6].

Zhang et al. found that the thickness of the smoke layer and the smoke outflow rate were both positively correlated with the inclination angle of a tunnel, and the CO concentration was negatively correlated with this angle [7]. 
Furthermore, CO concentration decreased exponentially with the distance away from the fire source, and $\mathrm{Hu}$ et al. suggested that this concentration increased linearly with the height above the floor [8]. Through extensive experiments and theoretical investigations, $\mathrm{Hu}$ et al. presented a function of dimensionless $\mathrm{CO}$ concentration along a tunnel length and a function of difference between this concentration and the dimensionless smoke temperature along the tunnel length $[9,10]$. As far as large particle concentration, Hall et al. proved that the concentration near the surface markedly was different to those for a gaseous plume and suggested that this concentration reduces more rapidly with increasing distance [11]. Therefore, $\mathrm{Hu}$ et al. and Wang presented that the ratio of critical velocity of a near-wall fire to that of a central fire was ideally estimated to be 1.26 by theoretical analysis $[12,13]$.

In transport business process, those pollutants are mainly affected by the running vehicles, and it is ensured that the concentration of pollutants in the tunnel is within the safety range [14-17]. Carvel et al. investigated the effect of forced longitudinal ventilation during a tunnel fire, and they found that the estimated values of the expert system were larger than the experimental values [18]. Ryu et al. investigated the flow field of a jet fan by conducting experiments and numerical simulations. They found that the negative pressure in front of the fan, distance between the fan and the wall, and roughness of the wall influence the jet performance [19]. Wang et al. carried out numerical simulations to investigate the influence of traffic wind formed by a vehicle on the ventilation of curved tunnels. They concluded that, for a curved tunnel with a radius greater than $2,000 \mathrm{~m}$, the differences between the straight-curve lines could be ignored [20]. Through model experiments, Fang et al. proposed that the angle between the inlet and the driving direction should be $6^{\circ}$ to help the traffic wind and that the angle between the outlet and the driving direction should not exceed $30^{\circ}[21,22]$. However, for longitudinal ventilation with supply-exhaust shafts, there always exist problems such as high construction costs and high operating energy consumption. By considering the uneven ventilating load of the up and down lines in an extra-long highway tunnel, whose ventilation shafts had a high construction cost or reduced excavation probability, Berner and Day proposed a ventilation concept for long twin-tube tunnels [23]. By conducting model experiments and numerical simulations, Zhang validated and verified the design parameters and applied them to the complementary doublehole ventilation of the Jingping tunnel [24]. Based on experimental data, Wang et al. investigated the flow field in a tunnel by applying double-hole ventilation and then proceeded to demonstrate the feasibility of this ventilation system [25]. Owing to the longitudinal slope and traffic quantity, the ventilation of long twin-tube tunnels is suitable for a highway tunnel with a length from $4 \mathrm{~km}$ to $7 \mathrm{~km}$ [26]. Theoretically, the length of the tunnel does not restrict the use of a CCV system; additionally, this system can reduce the number of ventilation shafts or directly avoid their excavation. Therefore, a CCV is an economical and efficient ventilation system.
A CCV performs fresh air suction, removes pollutants, recycles circulating air, and dilutes the pollutants in the downstream zone. However, a CCV has certain limitations and is not applicable to all situations. To clarify the applicability range of the $\mathrm{CCV}$, the objective of this study is to summarize the equations for calculating CAV, diluting smoke-dust and CO. Firstly, five dimensionless ratios are defined to quantify the differences of two CAV-diluted pollutants. Secondly, these equations are calculated numerically. Finally, this study will be expected to provide a reference for the application of CCV to extra-long highway tunnels.

\section{Materials and Methods}

2.1. CCV System. In a CCV system (Figure 1), first, a certain amount of fresh air is drawn in from the entrance of a tunnel. When the fresh air is contaminated to a certain extent, one part of this airflow flows into the short duct of the tunnel and is polluted to the possible highest degree. Additionally, it is ensured that the concentration of pollutants in the short duct is within allowable limits. The other part of this airflow is drawn out of the tunnel and flows through a deduster arranged in the circulating air roadway. Then, this drawn airflow is dedusted and purified, and thereby it transforms into a recycled airflow. Subsequently, this recycled airflow mixes with the more polluted airflow, and the mixed airflow dilutes the contaminants in the downstream tunnel continuously.

2.2. CAV Diluting Pollutants and Determination of RAV. According to a previous study [27], the pollutants in a tunnel are considered to be mainly smoke-dust and CO. Usually, the CAV dilution of these pollutants is not larger than the required air volume (RAV) and can be determined by calculating the contaminant emission. The smoke-dust emission is expressed as follows:

$$
\begin{aligned}
Q_{\mathrm{VI}}= & \frac{1}{3.6 \times 10^{6}} \cdot q_{\mathrm{VI}} \cdot f_{\mathrm{a}(\mathrm{VI})} \cdot f_{\mathrm{d}} \cdot f_{\mathrm{h}(\mathrm{VI})} \cdot f_{\mathrm{iv}(\mathrm{VI})} \cdot L \\
& \cdot \sum_{m=1}^{n_{\mathrm{D}}}\left(N_{m} \cdot f_{m(\mathrm{VI})}\right),
\end{aligned}
$$

where $Q_{\mathrm{VI}}$ is the smoke-dust emission $\left(\mathrm{m}^{2} / \mathrm{s}\right) ; q_{\mathrm{VI}}$ is the baseline smoke-dust emission $\left(\mathrm{m}^{2} /(\mathrm{veh} \cdot \mathrm{km})\right) ; f_{\mathrm{a}(\mathrm{VI})}$ is the vehicle condition coefficient (dimensionless number); $f_{\mathrm{d}}$ is the coefficient of vehicle density (dimensionless number); $f_{\mathrm{h}(\mathrm{VI})}$ is the coefficient of altitude (dimensionless number); $f_{\text {iv (VI) }}$ is the coefficient of longitudinal slope and vehicle speed (dimensionless number); $L$ is the tunnel length $(\mathrm{m}) ; f_{m(\mathrm{VI})}$ is the diesel vehicle type coefficient (dimensionless number); $n_{\mathrm{D}}$ is the diesel vehicle type number (dimensionless number); and $N_{\mathrm{m}}$ is the traffic quantity of the corresponding type (veh/h).

Then, the amount of CAV diluting smoke-dust is expressed as follows:

$$
Q_{\text {req }(\mathrm{VI})}=\frac{Q_{\mathrm{VI}}}{\delta_{\mathrm{VI}}}
$$

where $Q_{\text {req (VI) }}$ is CAV of diluted smoke-dust $\left(\mathrm{m}^{3} / \mathrm{s}\right)$ and $\delta_{\mathrm{VI}}$ is the smoke-dust concentration in design $\left(\mathrm{m}^{-1}\right)$. 


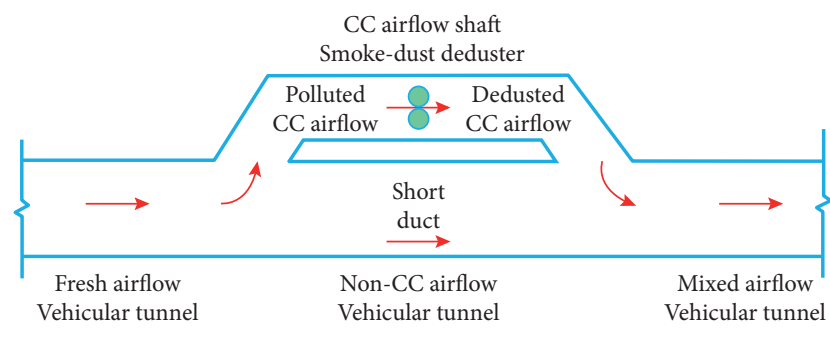

Figure 1: A CCV system.

The emission of $\mathrm{CO}$ is expressed as follows:

$$
\begin{aligned}
Q_{\mathrm{CO}}= & \frac{1}{3.6 \times 10^{6}} \cdot q_{\mathrm{CO}} \cdot f_{\mathrm{a}(\mathrm{CO})} \cdot f_{\mathrm{d}} \cdot f_{\mathrm{h}(\mathrm{CO})} \cdot f_{\mathrm{iv}(\mathrm{CO})} \cdot L \\
& \cdot \sum_{m=1}^{n}\left(N_{m} \cdot f_{m(\mathrm{CO})}\right),
\end{aligned}
$$

where $Q_{\mathrm{CO}}$ is the $\mathrm{CO}$ emission $\left(\mathrm{m}^{2} / \mathrm{s}\right) ; q_{\mathrm{CO}}$ is the baseline $\mathrm{CO}$ emission $\left(\mathrm{m}^{2} /(\mathrm{veh} \cdot \mathrm{km})\right) ; f_{\mathrm{a}(\mathrm{CO})}$ is the coefficient of vehicle condition (dimensionless number); $f_{\mathrm{d}}$ is the coefficient of vehicle density (dimensionless number); $f_{\mathrm{h}(\mathrm{CO})}$ is the coefficient of altitude (dimensionless number); $f_{\mathrm{iv}(\mathrm{CO})}$ is the coefficient of longitudinal slope and vehicle speed (dimensionless number); $f_{m(\mathrm{CO})}$ is the vehicle-type coefficient (dimensionless number); $n$ is the vehicle-type number (dimensionless number); and $N_{m}$ is the traffic quantity of corresponding type (veh/h).

The CAV diluting $\mathrm{CO}$ is expressed as follows:

$$
Q_{\text {req }(\mathrm{CO})}=10^{6} \cdot \frac{Q_{\mathrm{CO}}}{\delta_{\mathrm{CO}}} \cdot \frac{p_{0}}{p} \cdot \frac{T}{T_{0}},
$$

where $Q_{\text {req(CO) }}$ is the CAV diluting $\mathrm{CO}\left(\mathrm{m}^{3} / \mathrm{s}\right) ; p_{0}$ is the standard atmospheric pressure $(101.325 \mathrm{kPa}) ; p$ is the atmospheric pressure in the tunnel location $(\mathrm{kPa}) ; T_{0}$ is the standard temperature $(273.17 \mathrm{~K}) ; \mathrm{T}$ is the summer temperature at the tunnel location $(\mathrm{K})$; and $\delta_{\mathrm{CO}}$ is the design concentration of $\mathrm{CO}(\mathrm{ppm})$.

The CAV of the replacement air in a tunnel can be determined by the number of replacement times or the suggested velocity of the replacement. The equation is calculated by the number of replacement times and is expressed as follows:

$$
Q_{\mathrm{req}(\mathrm{ac})}=\frac{\left(A_{\mathrm{r}} \cdot L \cdot n_{\mathrm{s}}\right)}{3600},
$$

where $Q_{\text {req (ac) }}$ is the CAV of the replacement air in a tunnel $\left(\mathrm{m}^{3} / \mathrm{s}\right) ; A_{\mathrm{r}}$ is the net sectional area of the tunnel $\left(\mathrm{m}^{2}\right) ;$ and $n_{\mathrm{s}}$ is the minimum replacement times (times/h).

Additionally, the CAV is calculated by the suggested velocity of the replacement as follows:

$$
Q_{\text {req (ac) }}=v_{\mathrm{ac}} A_{\mathrm{r}} \text {, }
$$

where $v_{\mathrm{ac}}$ is the suggested velocity in the tunnel and cannot be less than $1.5 \mathrm{~m} / \mathrm{s}$.

By comparing the result obtained from Equation (5) with that obtained from Equation (6), we can determine the largest value, which will be the CAV of the replacement air in the tunnel. Moreover, by comparing the CAV diluting smoke-dust with the CAV diluting $\mathrm{CO}$ and CAV replacement, we can determine the largest of the three consumed air volumes, which will be the RAV of the CCV system in an extra-long highway tunnel.

2.3. Dimensionless Smoke-Dust to CO Ratios. In the previous section, the determination of the tunnel RAV was based on the calculation of the CAV diluting smoke-dust, CAV diluting CO, and CAV replacement air in a tunnel. When the amount of the CAV diluting smoke-dust is greater than that of the diluted $\mathrm{CO}$, the recycled airflow is produced by a deduster through the purifying part of the polluted airflow. However, it is quantifiable that the CAV diluting smoke-dust and $\mathrm{CAV}$ diluting $\mathrm{CO}$ are influenced by the tunnel length, environment, longitudinal slope, traffic quantity, and traffic composition in the tunnel. Moreover, it is not entirely clear if the above nonmechanical factors, CAV amounts, and their differences affect the CCV system.

Next, we present the definitions of the dimensionless ratios of the environmental parameters, longitudinal slope, diesel to gasoline, and ventilation load, respectively, and the critically dimensionless ratio of diesel to gasoline. First, by applying the coefficients of altitude in Equations (1) and (3) and by considering the atmospheric pressure ratio and temperature ratio, the environment ratio (dimensionless ratio of environmental parameters) is defined as follows:

$$
X=\frac{f_{\mathrm{h}(\mathrm{VI})}}{f_{\mathrm{h}(\mathrm{CO})}} \cdot \frac{P}{P_{0}} \cdot \frac{T_{0}}{T} .
$$

As shown in Equation (7), the environment ratio reflects the influence of the tunnel altitude and air temperature on the CAV diluting smoke-dust and CO.

The slope ratio (dimensionless ratio of the longitudinal slope) reflects the influence of the longitudinal slope on the CAV diluting smoke-dust and CO. By applying the longitudinal slope and vehicle speed coefficients in Equations (1) and (3), the slope ratio is defined as follows:

$$
Y=\frac{f_{\mathrm{iv}(\mathrm{VI})}}{f_{\mathrm{iv}(\mathrm{CO})}}
$$

The diesel-gasoline ratio reflects the influence of traffic quantity and traffic composition (proportion of diesel to gasoline engines) on the CAV diluting smoke-dust and CO. Using the coefficient of vehicle type, number of vehicle types, and the traffic quantity of Equations (1) and (3), the dieselgasoline ratio is expressed as follows:

$$
Z=\frac{\sum_{m=1}^{n_{\mathrm{D}}}\left(N_{m} \cdot f_{m(\mathrm{VI})}\right)}{\sum_{m=1}^{n}\left(N_{m} \cdot f_{m(\mathrm{CO})}\right)} .
$$

The load ratio (the dimensionless ratio of the ventilation load) reflects the difference between the ventilation load of the CAV diluting smoke-dust and CO. By substituting Equations (2) and (4) into Equations (7)-(9), the load ratio becomes proportional to the environment ratio, slope ratio, and dieselgasoline ratio. This load ratio is expressed as follows: 


$$
W=\frac{Q_{\text {req }(\mathrm{VI})}}{Q_{\mathrm{req}(\mathrm{CO})}}=\frac{1}{10^{6}} \cdot \frac{\delta_{\mathrm{CO}}}{\delta_{\mathrm{VI}}} \cdot \frac{q_{\mathrm{VI}}}{q_{\mathrm{CO}}} X \cdot Y \cdot Z .
$$

The critical diesel-gasoline ratio (critical dimensionless ratio of diesel to gasoline) reflects the number of the dieselgasoline ratio when the load ratio is equal to 1 . By setting $W=1$ in Equation (10), the critical diesel-gasoline ratio is expressed as follows:

$$
Z_{\mathrm{c}}=\frac{10^{6} \delta_{\mathrm{VI}}}{\delta_{\mathrm{CO}}} \cdot \frac{q_{\mathrm{CO}}}{q_{\mathrm{VI}}} \cdot \frac{1}{X} \frac{1}{Y}
$$

In the next section, the numerical calculations of Equations (7)-(11) are investigated, and the results are discussed with regard to the effects of the environment, slope, diesel-gasoline, load, and critical diesel-gasoline ratios on the CCV system.

\section{Results and Discussion}

3.1. Effect of Altitude on Environment Ratio. Fitting the two graphs of Figures 6.2.2 and 6.3.2 in the detailed rules 6.2 and 6.3 of Reference [27], there are the linear correlations of $f_{\mathrm{h}(\mathrm{VI})}=$ $(3 / 10000) H+(22 / 25)$ and $f_{\mathrm{h}(\mathrm{CO})}=(1 / 1800) H+(7 / 9) . H$ is the altitude height, and its unit is meter. Furthermore, the empirical correlation, which is related to atmosphere pressure with altitude height, temperature, and standard atmosphere pressure, is $P=P_{0} \cdot \exp [-(H / 29.28 T)]$ (29.28 is a dimensionless fitting constant). Substituting three correlations into Equation (7), and setting $T$ (tunnel site temperatures in summer) to $273 \mathrm{~K}, 283 \mathrm{~K}, 293 \mathrm{~K}$, and $303 \mathrm{~K}$, the calculated results are shown in Figure 2.

As shown in Figure 2, the environment ratio decreases with the increase of the tunnel's altitude and summer temperature. First, the effects of air temperature on the environment ratio are smaller than the effects of altitude. Second, as the altitude increases, it gradually decreases the curvature of the curve that relates the ratio to altitude. Specifically, the influence of the environment ratio with an altitude lower than $1,000 \mathrm{~m}$ is smaller than the influence of the environment ratio with an altitude over $1,000 \mathrm{~m}$. Therefore, the environment ratio is affected more by the altitude when the altitude is lower than $1,000 \mathrm{~m}$.

Moreover, the following conclusions can be drawn with regard to the results of Equation (10): with the increase of the tunnel's altitude, the environment ratio and the load ratio decrease. Additionally, the smaller the difference is between the CAV diluting smoke-dust and the CAV diluting CO, the more difficult the implementation of the CCV in the tunnel is. This reason is this CCV only handles smoke-dust by a deduster, meanwhile the control of $\mathrm{CO}$ concentration is depended on the exhaust airflow and supply airflow as same as the longitudinal ventilation with supply-exhaust shafts.

3.2. Effects of Driving Speed, Slope, and Diesel-Gasoline Ratio on Load Ratio. It is listed in Tables 1-3 that the slopes are related with $f_{\text {iv (VI) }}$ and $f_{\text {iv (CO) }}$ under the conditions of three driving speeds [27].

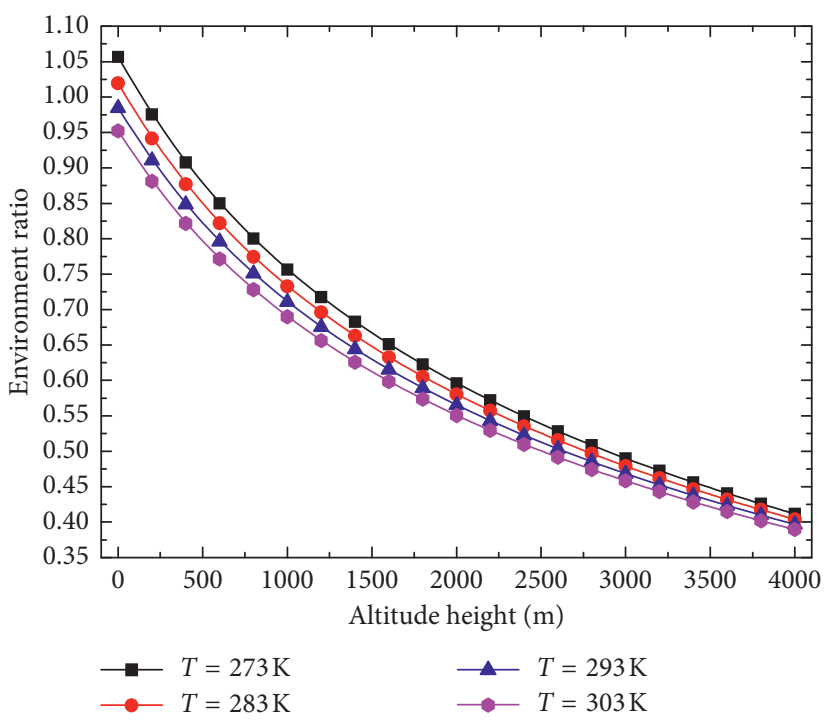

FIgURE 2: Change of the environment ratio with altitude of the tunnel.

Applied in Equation (8), $Y$ are calculated out by the data in Tables $1-3$; in the next, $\delta_{\mathrm{CO}} / \delta_{\mathrm{VI}}$ are $200 \mathrm{ppm} / 0.0090 \mathrm{~m}^{-1}$, $100 \mathrm{ppm} / 0.0065 \mathrm{~m}^{-1}$, and $100 \mathrm{ppm} / 0.0050 \mathrm{~m}^{-1}$ on the conditions of $10 \mathrm{~km} / \mathrm{h}, 40 \mathrm{~km} / \mathrm{h}$, and $80 \mathrm{~km} / \mathrm{h}$ driving speeds, respectively [27]; furthermore, referenced to the data in ventilation design of the Jiaozhouwan tunnel in Qingdao, Shandong, P. R. of China, the baselines of the CO emission and dust-smoke are $0.01 \mathrm{~m}^{2} /(\mathrm{veh} \cdot \mathrm{km})$ and $2.5 \mathrm{~m}^{2} /(\mathrm{veh} \cdot \mathrm{km})$, and annual decline ratios of those are 0.98 based on Reference [28]; lastly, setting environment ratio $X=1$, those data are substituted into Equation (10), and on the contrary, $Z$ are set as from 0.0 to 1.0 with the increment of 0.10 . The results are shown in Figures 3-5.

As shown in Figures 3-5, first, there exists a linear relationship between the load ratio, slope percentage, and diesel-gasoline ratio. Second, when the slope percentage and driving speed are constant, the load ratio increases with the increase of the diesel-gasoline ratio. This demonstrates that the RAV of the CCV system is mainly affected by the CAV diluting smoke-dust. Third, when the driving speed and diesel-gasoline ratio are kept constant, the load ratio increases with the increase of the slope percentage, which indicates that the RAV of the CCV system is mainly affected by the CAV diluting smoke-dust.

Fourth, the higher the driving speeds, the more obvious the divergence of the load ratio between the slope percentage of $1 \%$ and that of $0 \%$. Specifically, when the diesel-gasoline ratio is constant, the load ratio with a $0 \%$ slope percentage is far larger than that with a $1 \%$ slope percentage. Finally, by comparing Figures 3-5, it can be seen that the load ratio increases with the increase of driving speed under the condition of the slope percentage and the diesel-gasoline ratio being constant. Therefore, it can be concluded that the load ratio increases with the increase of driving speed, slope percentage, and dieselgasoline ratio. 
TABLE 1: Slope related with $f_{\text {iv (VI) }}$ and $f_{\text {iv }(\mathrm{CO})}(10 \mathrm{~km} / \mathrm{h}$, jamming condition).

\begin{tabular}{lccccccccc}
\hline Slope $(\%)$ & -4 & -3 & -2 & -1 & 0 & 1 & 2 & 3 & 4 \\
\hline$f_{\text {iv }(\mathrm{VI})}$ & 0.30 & 0.36 & 0.40 & 0.50 & 0.60 & 0.72 & 0.85 & 1.03 & 1.25 \\
$f_{\text {iv }(\mathrm{CO})}$ & 0.80 & 0.80 & 0.80 & 0.80 & 0.80 & 0.80 & 0.80 & 0.80 & 0.80
\end{tabular}

TABLe 2: Slope related with $f_{\text {iv }(\mathrm{VI})}$ and $f_{\text {iv }(\mathrm{CO})}(40 \mathrm{~km} / \mathrm{h}$, idling condition).

\begin{tabular}{lccccccccc}
\hline Slope $(\%)$ & -4 & -3 & -2 & -1 & 0 & 1 & 2 & 3 & 4 \\
\hline$f_{\text {iv }(\mathrm{VI})}$ & 0.30 & 0.40 & 0.55 & 0.70 & 0.85 & 1.10 & 1.45 & 2.20 & 2.95 \\
$f_{\text {iv }(\mathrm{CO})}$ & 1.00 & 1.00 & 1.00 & 1.00 & 1.00 & 1.00 & 1.00 & 1.00 & 1.00 \\
\hline
\end{tabular}

TABLE 3: Slope related with $f_{\mathrm{iv}(\mathrm{VI})}$ and $f_{\mathrm{iv}(\mathrm{CO})}(80 \mathrm{~km} / \mathrm{h}$, design condition).

\begin{tabular}{lccccccccc}
\hline Slope $(\%)$ & -4 & -3 & -2 & -1 & 0 & 1 & 2 & 3 & 4 \\
\hline$f_{\text {iv }(\mathrm{VI})}$ & 0.30 & 0.40 & 0.55 & 0.80 & 1.30 & 2.60 & 3.70 & 4.40 & 5.00 \\
$f_{\text {iv }(\mathrm{CO})}$ & 1.00 & 1.00 & 1.00 & 1.00 & 1.00 & 1.00 & 1.20 & 1.20 & 1.20 \\
\hline
\end{tabular}

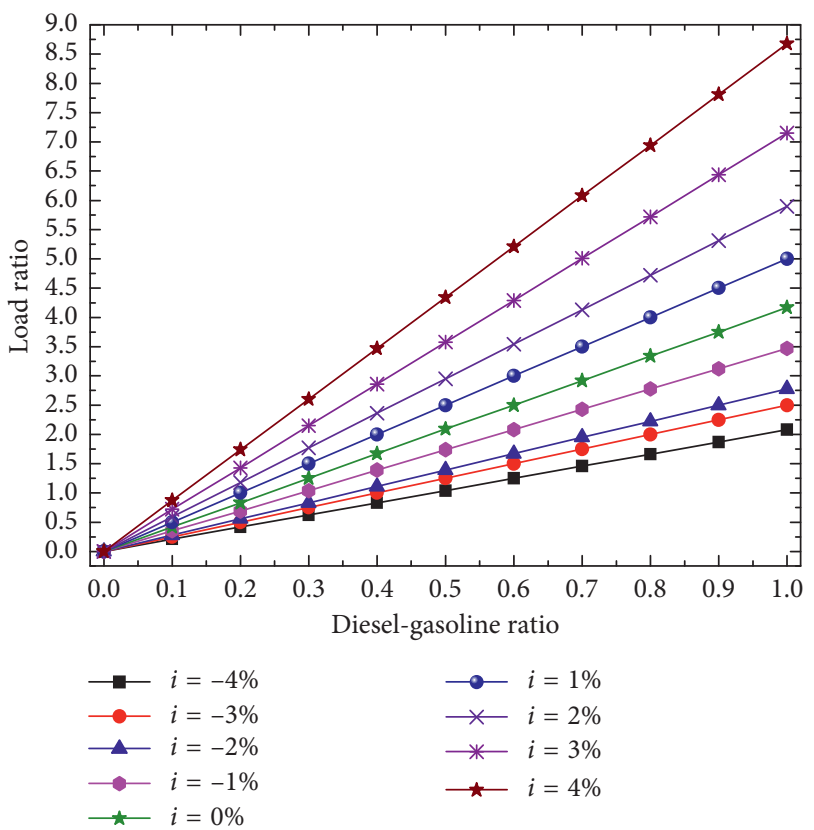

FIgURE 3: Load ratios changing with slope percentage $(10 \mathrm{~km} / \mathrm{h}$, jamming condition).

3.3. Effects of Driving Speed and Slope on Critical DieselGasoline Ratio. Based on Reference [27] and calculation, the slope ratios $Y=f_{\mathrm{iv}(\mathrm{VI})} / f_{\mathrm{iv}(\mathrm{CO})}$ change with the slope percentages under the conditions of eight driving speeds, as listed in Table 4.

$\delta_{\mathrm{CO}}$ and $\delta_{\mathrm{VI}}$ are listed in Table 5 [27], and $\delta_{\mathrm{CO}} / \delta_{\mathrm{VI}}$ can be calculated out; secondly, $Y$ is valuated by the data of Table 4; thirdly, referenced to the data in ventilation design of the Jiaozhouwan tunnel in Qingdao, Shandong, P. R. of China, the baselines of the $\mathrm{CO}$ emission and dust-smoke are $0.01 \mathrm{~m}^{2} /(\mathrm{veh} \cdot \mathrm{km})$ and $2.5 \mathrm{~m}^{2} /(\mathrm{veh} \cdot \mathrm{km})$, and an annual decline ratio of those are 0.98 based on Reference [28]; lastly, setting environment ratio $X=1$, those data are substituted

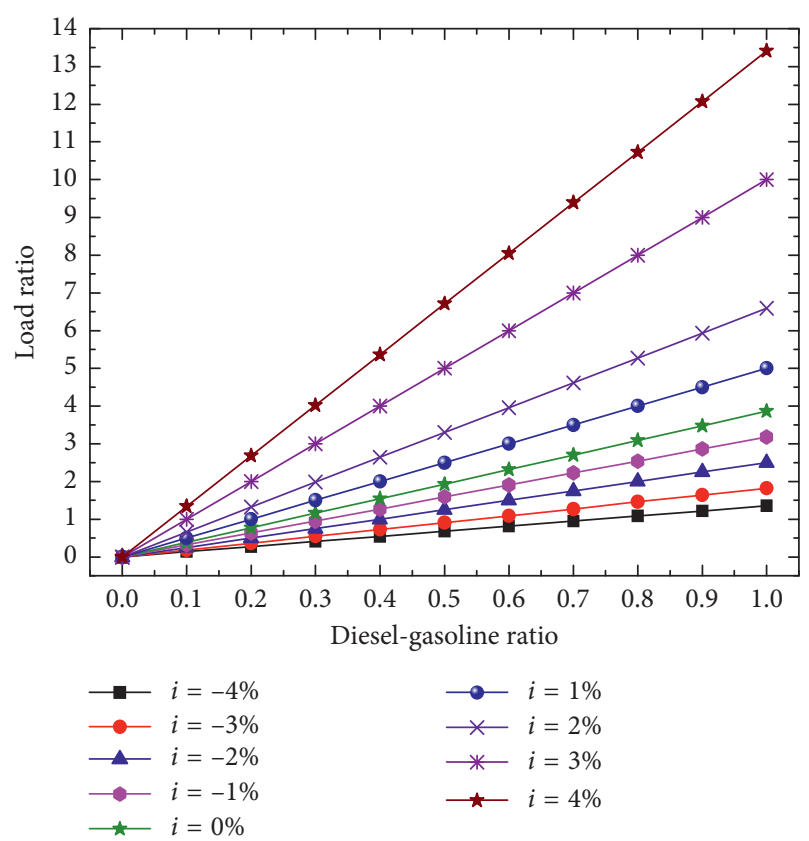

Figure 4: Load ratios changing with slope percentage $(40 \mathrm{~km} / \mathrm{h}$, idling condition).

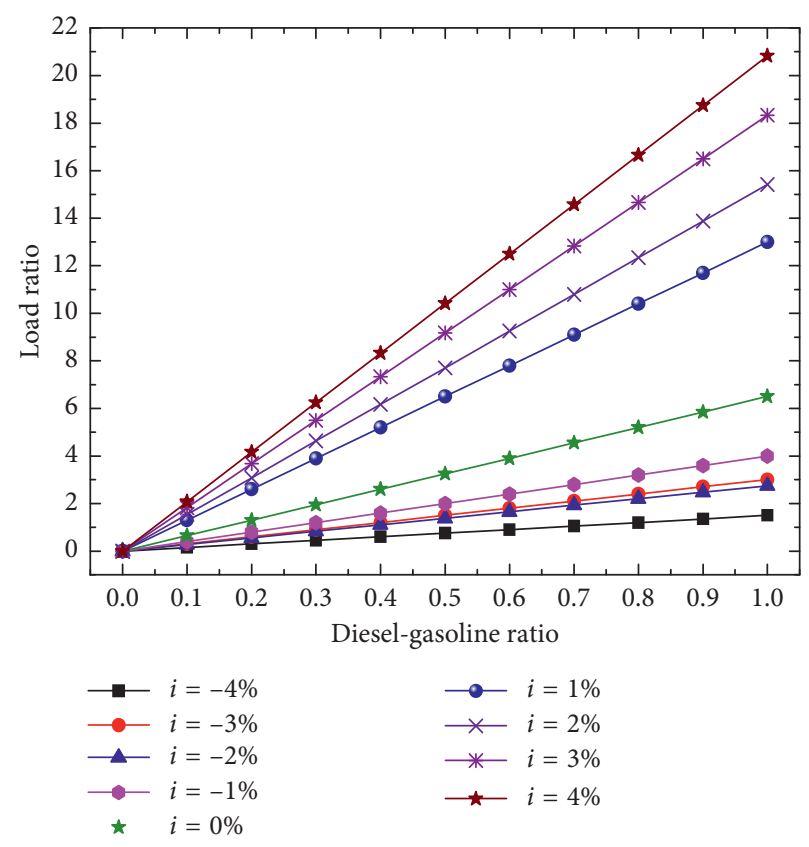

FIgURE 5: Load ratios changing with slope percent $(80 \mathrm{~km} / \mathrm{h}$, design condition).

into Equation (11) of the critical diesel-gasoline ratio when $W=1$ of Equation (10), and the results of the critical dieselgasoline ratio are shown in Figure 6.

First, the critical diesel-gasoline ratio decreases with the increase of the slope percentage. Second, when the driving speed is higher than $40 \mathrm{~km} / \mathrm{h}$, the critical diesel-gasoline ratio decreases with the increase of driving speed. Conversely, when the driving speed is lower than $40 \mathrm{~km} / \mathrm{h}$, this ratio decreases with the increase of driving speed under the 
TABLE 4: $Y=f_{\mathrm{iv}(\mathrm{VI})} / f_{\mathrm{iv}(\mathrm{CO})}$ related with slope percentages and driving speeds.

\begin{tabular}{lccccccccc}
\hline Slope (\%) & -4 & -3 & -2 & -1 & 0 & 1 & 2 & 3 \\
\hline $80 \mathrm{~km} / \mathrm{h}$ & 0.30 & 0.40 & 0.55 & 0.80 & 1.30 & 2.60 & 3.08 & 3.67 & 4.17 \\
$70 \mathrm{~km} / \mathrm{h}$ & 0.30 & 0.40 & 0.55 & 0.80 & 1.10 & 1.80 & 3.10 & 3.25 \\
$60 \mathrm{~km} / \mathrm{h}$ & 0.30 & 0.40 & 0.55 & 0.75 & 1.00 & 1.45 & 2.20 & 2.95 \\
$50 \mathrm{~km} / \mathrm{h}$ & 0.30 & 0.40 & 0.55 & 0.75 & 1.00 & 1.45 & 2.20 & 2.95 \\
$40 \mathrm{~km} / \mathrm{h}$ & 0.30 & 0.40 & 0.55 & 0.70 & 0.85 & 1.10 & 1.45 & 2.20 & 3.75 \\
$30 \mathrm{~km} / \mathrm{h}$ & 0.38 & 0.50 & 0.63 & 0.75 & 0.90 & 0.90 & 1.10 & 1.45 \\
$20 \mathrm{~km} / \mathrm{h}$ & 0.38 & 0.45 & 0.50 & 0.63 & 0.75 & 0.72 & 0.85 & 1.03 \\
$10 \mathrm{~km} / \mathrm{h}$ & 0.38 & 0.45 & 0.50 & 0.63 & 0.75 & 0.90 & 1.06 & 1.29 & 1.25 \\
\hline
\end{tabular}

TABLE 5: $\delta_{\mathrm{CO}}$ and $\delta_{\mathrm{VI}}$ related with driving speed.

\begin{tabular}{lcccccccc}
\hline Speed $(\mathrm{km} / \mathrm{h})$ & 80 & 70 & 60 & 50 & 40 & 30 & 20 & 10 \\
\hline$\delta_{\mathrm{CO}}(\mathrm{ppm})$ & 100 & 100 & 100 & 100 & 100 & 125 & 200 \\
$\delta_{\mathrm{VI}}\left(\mathrm{m}^{1}\right)$ & 0.0050 & 0.0055 & 0.0055 & 0.0060 & 0.0065 & 0.0070 & 0.0080 & 0.0090 \\
\hline
\end{tabular}

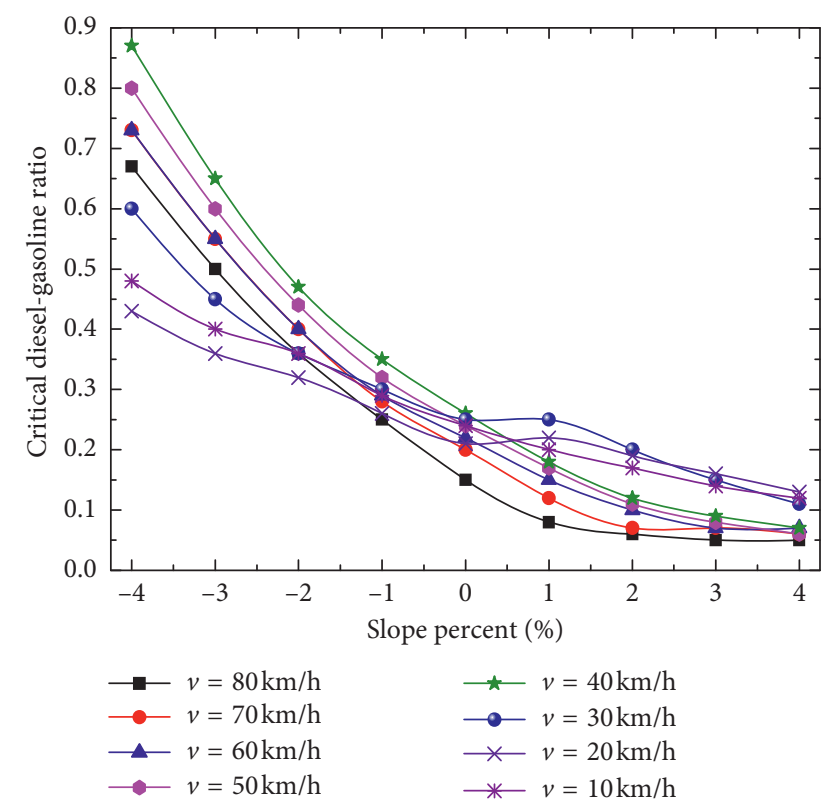

Figure 6: Critical diesel-gasoline ratio changing with slope and driving speed. " $v$ " is notated with "driving speed".

condition of the slope being larger than $1 \%$. Third, when the slope is smaller than $1 \%$, the critical ratio varies greatly; on the contrary, when the slope is larger than $1 \%$, the critical ratio changes slowly. Moreover, these critical ratios are obviously smaller than the values obtained with a slope of less than $1 \%$. Finally, when the slope is greater than $1 \%$ and the critical diesel-gasoline ratio is greater than 0.25 , the load ratio of the tunnel ventilation system will be larger than 1 . Under the abovementioned conditions, the CCV can be applied to the tunnel ventilation system.

\section{Conclusions}

By referring to the existing equations, this paper presented the deduction of equations of five ratios with a dimensionless number and CCV. Additionally, a theoretical relationship between the CCV and CAV diluting smoke-dust and CO was established. Moreover, the numerical calculation of the equations was carried out. The main conclusions drawn from this study are as follows:

(1) When the load ratio is not lower than 1, the tunnel can be ventilated by the CCV in advantage of energy saving and high efficiency.

(2) When the load ratio is equal to 1 , the key indicator of an applicable CCV system is the critical dieselgasoline ratio.

\section{Data Availability}

The data used to support the findings of this study are available from the corresponding author upon request.

\section{Conflicts of Interest}

The authors declare no conflicts of interest.

\section{Acknowledgments}

We thank Liwen Bianji, Edanz Editing China (http://www. liwenbianji.cn/ac), for editing the English text of a draft of this manuscript. The authors are grateful for the financial support received from the National Natural Science Foundation of China (Grant Nos. 51574123, 51774134, and 51864014), the Project of Scientific Research Fund of the Hunan Provincial Education Department (Grant No. 16B094), and the Doctor Research Fund of Hunan University of Science and Technology (Grant No. E51681).

\section{References}

[1] D. M. De Faveri, A. Vidili, R. Pastorino, and G. Ferraiolo, "Wind effects on diffusion flames of fires of high source momentum," Journal of Hazardous Materials, vol. 22, no. 1, pp. 85-100, 1989.

[2] Y. Wang, J. Jiang, and D. Zhu, "Diesel oil pool fire characteristic under natural ventilation conditions in tunnels with 
roof openings," Journal of Hazardous Materials, vol. 166, no. 1, pp. 469-477, 2009.

[3] L. H. Hu, S. Liu, W. Peng, and R. Huo, "Experimental study on burning rates of square/rectangular gasoline and methanol pool fires under longitudinal air flow in a wind tunnel," Journal of Hazardous Materials, vol. 169, no. 1, pp. 972-979, 2009.

[4] C. Wang, J. Guo, Y. Ding, J. Wen, and S. Lu, "Burning rate of merged pool fire on the hollow square tray," Journal of Hazardous Materials, vol. 290, pp. 78-86, 2015.

[5] C. Tao, Y. He, Y. Li, and X. Wang, "Effects of oblique air flow on burning rates of square ethanol pool fires," Journal of Hazardous Materials, vol. 260, pp. 552-562, 2013.

[6] L. Yi, R. Wei, J. Peng, T. Ni, Z. Xu, and D. Wu, "Experimental study on heat exhaust coefficient of transversal smoke extraction system in tunnel under fire," Tunnelling and Underground Space Technology, vol. 49, pp. 268-278, 2015.

[7] J. Zhang, X. Zhou, Q. Xu, and L. Yang, "The inclination effect on CO generation and smoke movement in an inclined tunnel fire," Tunnelling and Underground Space Technology, vol. 29, pp. 78-84, 2012.

[8] L. H. Hu, N. K. Fong, L. Z. Yang, W. K. Chow, Y. Z. Li, and R. Huo, "Modeling fire-induced smoke spread and carbon monoxide transportation in a long channel: fire dynamics simulator comparisons with measured data," Journal of Hazardous Materials, vol. 140, no. 1, pp. 293-298, 2007.

[9] L. H. Hu, F. Tang, D. Yang, S. Liu, and R. Huo, "Longitudinal distributions of $\mathrm{CO}$ concentration and difference with temperature field in a tunnel fire smoke flow," International Journal of Heat and Mass Transfer, vol. 53, no. 13, pp. 2844-2855, 2010.

[10] F. Tang, L. H. Hu, L. Z. Yang, Z. W. Qiu, and X. C. Zhang, "Longitudinal distributions of CO concentration and temperature in buoyant tunnel fire smoke flow in a reduced pressure atmosphere with lower air entrainment at high altitude," International Journal of Heat and Mass Transfer, vol. 75, pp. 130-134, 2014.

[11] D. J. Hall, V. Kukadia, S. Walker, and G. W. Marsland, "Deposition of large particles from warehouse fire plumes-a small-scale wind tunnel model study," ournal of Hazardous Materials, vol. 59, no. 1, pp. 13-29, 1998.

[12] L. H. Hu, W. Peng, and R. Huo, "Critical wind velocity for arresting upwind gas and smoke dispersion induced by nearwall fire in a road tunnel," Journal of Hazardous Materials, vol. 150, no. 1, pp. 68-75, 2008.

[13] H. Y. Wang, "Prediction of soot and carbon monoxide production in a ventilated tunnel fire by using a computer simulation," Fire Safety Journal, vol. 44, no. 3, pp. 394-406, 2009.

[14] Y. X. Xia, Y. D. Wang, and F. Zhao, "Ventilation scheme of Zhongnanshan highway tunnel in Qinling," Journal of Chang'an University (Natural Science Edition), vol. 22, no. 5, pp. 48-50, 2002.

[15] Y.X. Xia, J. X. Zhang, and Y. D. Wang, "Ventilation scheme of Yan Menguan highway tunnel," Journal of Chang'an University (Natural Science Edition), vol. 23, no. 4, pp. 46-50, 2003.

[16] G. S. Kwa, "The design of tunnel ventilation system for a long vehicular tunnel," Tunnelling \& Underground Space Technology, vol. 19, no. 4-5, p. 312, 2004.

[17] K. C. Lu and Y. M. Wu, "Discussion of several problems in ventilation design for highway tunnel," Highway, vol. 35, no. 5, pp. 223-227, 2006.

[18] R. O. Carvel, A. N. Beard, and P. W. Jowitt, "The influence of longitudinal ventilation systems on fires in tunnels,"
Tunnelling and Underground Space Technology, vol. 16, no. 1, pp. 3-21, 2001.

[19] J. H. Ryu, H. Y. Yong, and K. Jin, "The jet-fan model test for a road tunnel ventilation," Korean Journal of Air-Conditioning and Refrigeration Engineering, vol. 15, no. 8, pp. 630-641, 2003.

[20] F. Wang, M. Wang, S. He, and Y. Deng, "Computational study of effects of traffic force on the ventilation in highway curved tunnels," Tunnelling and Underground Space Technology Incorporating Trenchless Technology Research, vol. 26, no. 3, pp. 481-489, 2011.

[21] L. Fang, Y. L. Xie, and N. J. Li, "Study on the optimum angle between the exhausting duct orifice and the longitudinal axis of a highway tunnel with longitudinal ventilation through shafts by model test," Modern Tunnelling Technology, vol. 42, no. 5, pp. 35-39, 2005.

[22] L. Fang, Y. L. Xie, and X. H. Yang, "Optimized model of air supply outlet angle in highway tunnel blowing and exhausting longitudinal ventilation system," Journal of Chang'an University (Natural Science Edition), vol. 29, no. 4, pp. 69-72, 2009.

[23] M. A. Berner and J. A. Day, "A new concept for ventilation long twin-tube tunnels," Process 7th International Symposium on the Aerodynamics and Ventilation of Vehicle Tunnels, vol. 6, no. 3, p. 358, 1991.

[24] G. P. Zhang, Research on Bidirectional Air Inter-Exchange Longitudinal Ventilation in Road Tunnels, Southwest Jiaotong University, Chengdu, China, 2008.

[25] Y. Q. Wang, F. Y. Xia, and Y. L. Xie, "Physical model experiment on complementary ventilation of extra-long highway tunnel," China Journal of Highway and Transport, vol. 27, no. 6, pp. 84-90, 2014.

[26] Y. Q. Wang, X. M. Jiang, and Y. K. Wu, “Applicability analysis of the complementary ventilation system in twin-tube highway tunnels," Modern Tunnelling Technology, vol. 52, no. 3, pp. 14-22, 2015.

[27] Ministry of Communications of the PRC, JTJ/T D70/2-022014 Guidelines for Design of Ventilation of Highway Tunnels, People's Communications Publishing House, Beijing, China, 2014.

[28] Technical Committee 5 Road Tunnels, Road Tunnels: Vehicle Emissions and Air Demand for Ventilation, PIARC, Paris, France, 2004. 


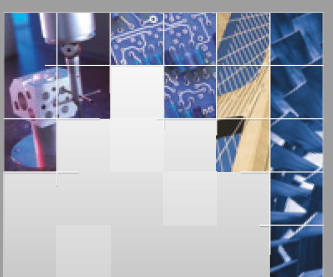

\section{Enfincering}
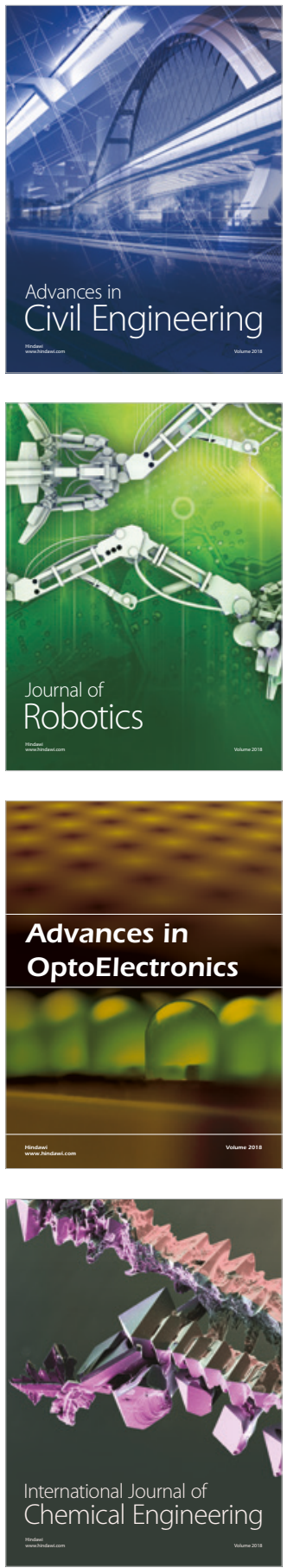

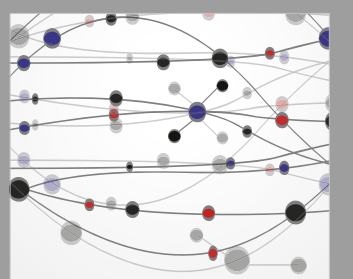

\section{Rotating \\ Machinery}

The Scientific World Journal

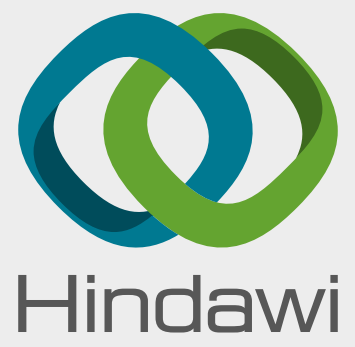

Submit your manuscripts at

www.hindawi.com
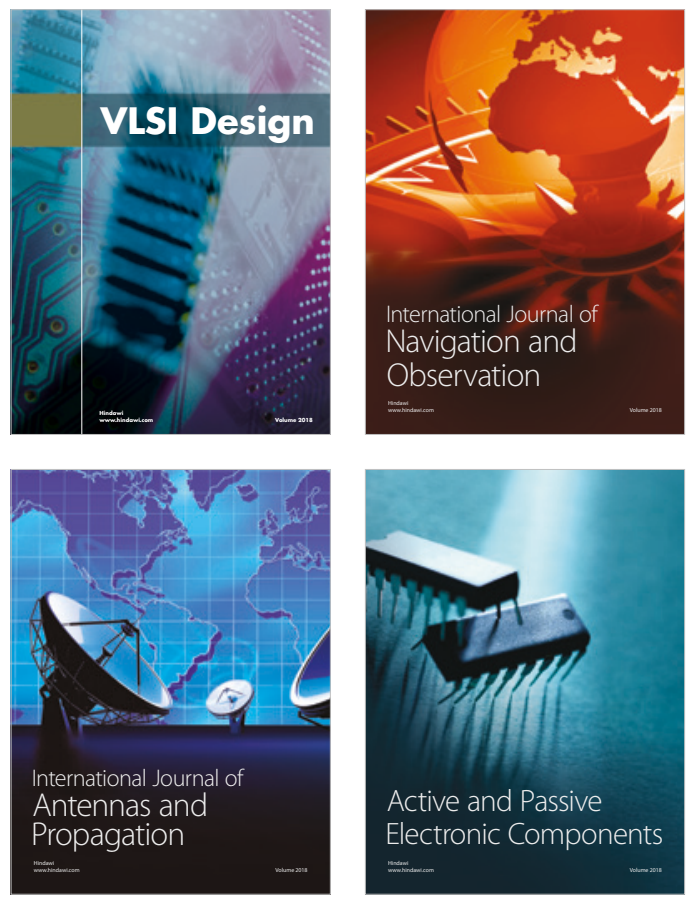
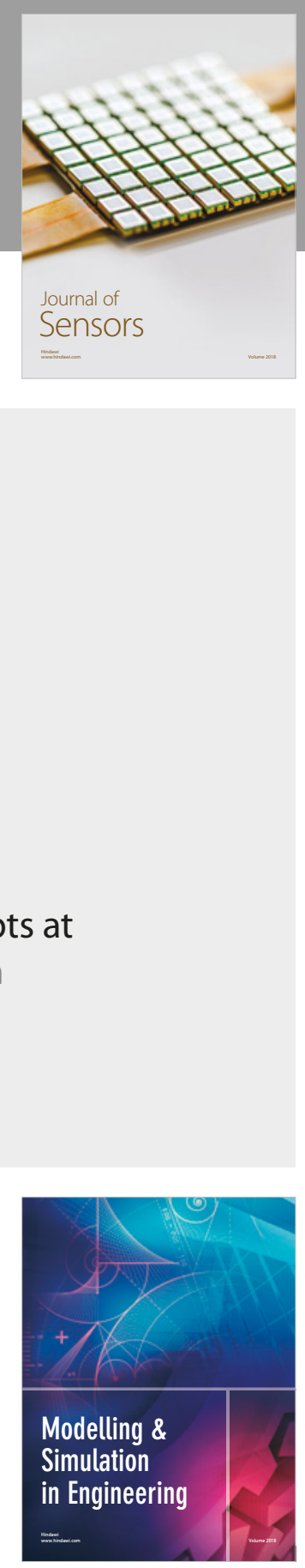

\section{Advances \\ Multimedia}
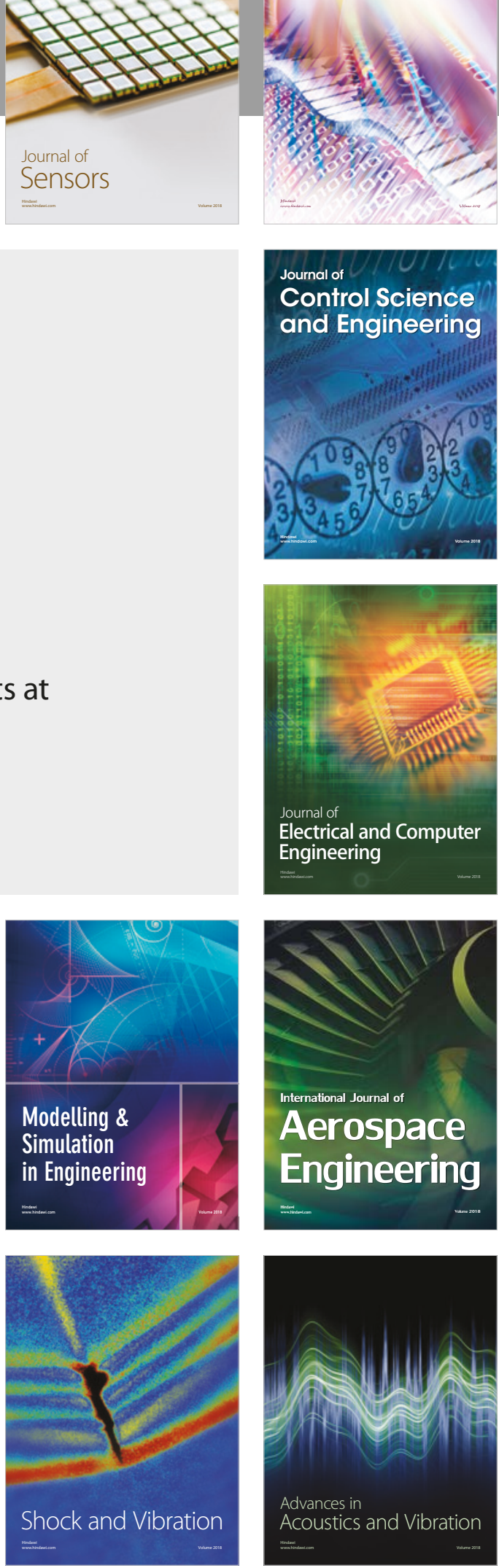